\title{
CONSTRUINDO UMA METODOLOGIA DE PESQUISA POPULAR E FEMINISTA JUNTO AO MMC EM SANTA CATARINA \\ Maria Teresa Muraca*
}

\begin{abstract}
Resumo
A partir da análise de algumas dimensões do percurso de pesquisa que estou conduzindo desde 2012 junto ao Movimento de Mulheres Camponesas em Santa Catarina, pretendo dialogar com o debate internacional sobre a crise da concepção moderna de método científico e a busca por práticas metodológicas capazes de superar suas mortificadoras visões dualistas. Em particular, quero interrogar as implicações sobre as escolhas metodológicas do feminismo e da pedagogia popular enquanto opções teóricas, políticas e existenciais. Nesse sentido, através de um relato autoetnográfico da metodologia de "convivência itinerante" adotada na investigação, quero apresentar a pesquisa como uma construção dialógica e intersubjetiva, em que a pesquisadora, ao pesquisar, pesquisa-se e é pesquisada e as participantes, ao serem pesquisadas, pesquisam e pesquisam-se.
\end{abstract}

Palavras chave: Pesquisa de campo. Convivência itinerante. Dialogicidade.

\footnotetext{
* Doutoranda em co-tutela na Universidade de Verona em Itália (Programa de Doutorado em Ciências da Educação e da Formação Contínua) e da Universidade Federal de Santa Catarina (Programa de Pós-Graduação Interdisciplinar em Ciências Humanas).Email: m.muraca@hotmail.it
} 


\section{Introdução}

Durante o século XX, diferentes perspectivas epistemológicas contribuíram para questionar as definições de ciência e método científico vigentes desde a modernidade, tanto é que hoje elas não parecem mais ser sustentáveis seja do ponto de vista teórico, seja do ponto de vista social, pelas consequências destruidoras que geraram sobre os equilíbrios sociais e ecológicos (SANTOS, 1987). Nesse sentido, em nível internacional, existe um vivo debate orientado a elaborar novas perspectivas sobre o método e inéditas práticas de pesquisa, preocupadas em restituir relevância a dimensões até hoje marginalizadas e superar mortificadoras visões dualistas.

No intuito de dialogar com essa discussão, proponho em seguida um relato etnográfico, relativo à pesquisa que estou conduzindo desde 2012 junto ao Movimento das Mulheres Camponesas em Santa Catarina (MMC/SC). A pesquisa, em curso, é orientada a explorar as práticas político-pedagógicas do $\mathrm{MMC} / \mathrm{SC}$, valorizando sua contribuição para pensar a perspectiva da pedagogia popular em um sentido feminista.

Em particular, neste trabalho, pretendo mostrar que a assunção das implicações do feminismo e da educação popular como opções teóricas, políticas e existenciais para as escolhas metodológicas me conduziu a questionar muitas dicotomias clássicas entre, por exemplo, teoria e prática, academia e campo, pesquisadora e sujeitos da pesquisa, mente e corpo. São dimensões muito ligadas entre si, que tratarei privilegiando o questionamento da contradição entre pesquisadora e sujeitos da pesquisa. Ela tem uma relevância fundamental na ótica de educação popular e principalmente na obra de Freire, que a propõe como a marca distintiva da opção libertadora no trabalho educativo e científico com as comunidades empobrecidas. Nessa perspectiva, a pesquisa se torna um percurso em que a pesquisadora, ao pesquisar, pesquisa-se e é pesquisada, e as participantes, ao serem pesquisadas, pesquisam e pesquisam-se, sendo protagonistas, desde a escolha do tema até a devolução e discussão dos resultados, de um ato de criação, em que a afetividade e a amorosidade colocam-se como principais elementos para essa comunhão (OLIVEIRA, 2009).

Nesse sentido, a concepção em que situo minhas reflexões considera o método não como uma escolha disponível desde o começo da aventura cientifica, mas como uma construção 
(intersubjetiva) que se realiza durante o percurso de pesquisa.

De forma semelhante a uma viagem, embora não excluindo sequências programadas, o método requer criatividade, estratégia e capacidade de lidar com o imprevisto, por isso, mesmo não se reduzindo a uma experiência pessoal, tem um caráter contextual e situado (MORIN; CIURANA; MOTTA, 2004).

\section{A dialogicidade como condição de possibilidade do percurso da pesquisa}

Nas etnografias clássicas, a relação entre o pesquisador e seus informantes tinha uma importância periférica, sendo relegada geralmente aos capítulos introdutórios dos trabalhos antropológicos ou a livros-diários especificadamente dedicados ao assunto e considerados, mais do que verdadeira antropologia, relatos "literários" de experiências pessoais. Só em tempos mais recentes, graças sobretudo à revolução epistemológica introduzida pelo feminismo e pelos antropólogos pós-modernos, essa relação tem se afirmado como a dimensão central na construção das etnografias (GROSSI, 1992). Os defensores do paradigma dialógico e, em particular, Clifford (2008), têm criticado a tendência dos etnógrafos, de forma parecida aos críticos literários, em organizar os significados num texto caracterizado por uma única intenção coerente, filtrando a realidade das situações discursivas, banindo os aspectos dialógicos e situacionais da interpretação etnográfica e excluindo os informadores das etnografias legítimas. Os dados perdem assim sua dialogicidade através de formas textualizadas, os eventos e os encontros da pesquisa se transformam em evidências de uma realidade cultural englobante, e os atores específicos são separados das suas produções e substituídos por um único autor abstrato. Para corrigir essa tendência, Clifford (2008, p. 41) considera "necessário conceber a etnografia não como a experiência e a interpretação de uma 'outra' realidade circunscrita, mas sim como uma negociação construtiva envolvendo pelo menos dois - e muitas vezes mais - sujeitos conscientes e politicamente significativos". A categoria de polifonia que ele propõe traz para o centro a intersubjetividade e o contexto performativo da experiência etnográfica, ao mesmo tempo em que supera uma visão estática da realidade social como internamente homogênea em prol de uma visão mais problematizadora. Um 
1 As participantes da pesquisa citadas no texto me autorizaram a usar seus nomes autênticos. resultado significativo da discussão promovida pela antropologia pós-moderna e pela antropologia feminista foi que as práticas das pesquisadoras e dos pesquisadores, as modalidades como os sujeitos os acolhem e tornam sua presença possível no campo, as situações muitas vezes precárias em que a pesquisa se realiza deixaram de ser o pano de fundo e se colocaram como os elementos constitutivos da interpretação e do conhecimento etnográfico (MONTEIRO apud GROSSI, 1992).

Colocando-me no quadro dessas mudanças epistemológicas, afirmo que a dialogicidade representou a condição de possibilidade de todo meu percurso de pesquisa, sendo fundamental para ter acesso ao campo, formular e reformular o desenho e as perguntas da pesquisa, individuar os sujeitos envolvidos na indagação, negociar junto a eles as modalidades e os tempos da coleta dos dados e construir os instrumentos de pesquisa. Uma primeira figura chave nesse sentido foi uma coordenadora estadual do Movimento dos Trabalhadores Rurais Sem Terra (MST), Rosângela Pasquetti Garbin ${ }^{1}$, com quem compartilhei um apartamento em Florianópolis de março até junho de 2012. Encontrei Rosângela na secretaria do MST, que então cogitava como o sujeito principal da minha pesquisa e com quem, portanto, entrei em contato logo ao chegar em Florianópolis - cidade onde já tinha realizado uma experiência de estágio e pesquisa orientada à elaboração de minha dissertação junto ao Centro de Educação e Evangelização Popular (CEDEP), uma ONG que atende crianças e adolescentes da comunidade Monte Cristo.

Nos três meses em que eu e Rosângela moramos juntas, se consolidou uma relação que legitimou o meu acesso à realidade dos movimentos sociais do campo de Santa Catarina e que me permitiu entrar em contato com os sujeitos da pesquisa. De fato, Rosângela criou a ponte entre o Movimento das Mulheres Camponesas e eu, e me encorajou a focar a minha atenção sobre ele, em razão do seu maior desempenho de práticas e reflexões feministas, mais correspondentes aos meus interesses de pesquisa. Mas minha amizade com a Rosângela foi essencial também para a redefinição e a reformulação do objeto e das perguntas da pesquisa. Ainda que eu tivesse encontrado alguns movimentos do campo e da cidade durante minha experiência precedente de estágio e de pesquisa em Santa Catarina, e ainda que eu tivesse mantido com eles uma comunicação constante durante o tempo da minha permanência no meu país, a realidade com que eu me deparava 
no começo do ano passado era para mim, em muitos aspectos, inédita. As longas conversas com Rosângela, que ganhavam em profundidade com o passar do tempo, portanto, me permitiram compreender o momento atual vivido pelos movimentos do campo em Santa Catarina, os desafios mais significativos e as transformações mais importantes ocorridas durante os últimos anos. Revelando-me dimensões que foram tão importantes para o rumo que tomou o meu percurso de indagação, Rosângela participou da construção da minha pesquisa, através modalidades de que a categoria de "informante privilegiado" não consegue dar conta. Nesse sentido, proponho a categoria de interlocutor da pesquisa, que é capaz de expressar melhor a competência dos participantes. De fato, como tentarei mostrar na sequência, os interlocutores da pesquisa participam da construção do objeto e das perguntas da investigação, negociam a posição do pesquisador no interior da realidade social - tornando assim possível a relação de pesquisa - e interpretam e conhecem de uma forma igualmente relevante em comparação aos pesquisadores. Dessa forma, o pesquisador deixa de ser a única autoridade capaz de categorizar, representar e compreender os outros, tornando-se um ator social constantemente comprometido num processo de negociação e de troca, do qual emerge uma voz polifônica.

\section{Contextualização da pesquisa de campo}

Com essa legitimação, de março até junho de 2012 realizei a fase de exploração de minha pesquisa de campo, isto é, através de algumas saídas de campo, reformulei o desenho e as perguntas da investigação, negociei o acesso ao campo, individuei os sujeitos da pesquisa, construí os instrumentos de coleta dos dados e, sobretudo, concordei com a coordenação estadual do $\mathrm{MMC} /$ $\mathrm{SC}$ as modalidades de realização de um segundo momento de pesquisa de campo, caracterizado por uma imersão mais intensiva. De fato, o meu desejo de construir um conhecimento do $\mathrm{MMC} /$ $\mathrm{SC}$ a partir do dia a dia das mulheres que dele participam, me conduziu a pedir à coordenação para poder morar nas casas das militantes, sendo acolhida em uma das Regionais em que o movimento se articula a nível estadual. $\mathrm{O}$ meu pedido foi acolhido e a Coordenação Estadual do Movimento me propôs ser recebida na Regional de São José do Cedro, no Extremo Oeste de Santa Catarina, em razão do grande enraizamento que o MMC tem 
nesses lugares. De fato, o MMC nasceu em Santa Catarina, com o nome de Movimento das Mulheres Agricultoras (MMA), no começo dos anos 1980 na diocese de Chapecó - de que a região de São José do Cedro faz parte - por efeito, sobretudo, do clima de renovação eclesial inaugurada com o episcopado de Dom José Gomes e com a Teologia da Libertação.

Assim, de julho de 2012 até março de 2013 fui hospedada em cinco municípios da regional de São José do Cedro: Palma Sola, Anchieta, Guarujá do Sul, São José do Cedro, Dionísio Cerqueira, sendo acolhida nas casas de dezenove integrantes do movimento - em cada casa fiquei mais ou menos uma semana. Além de ter a oportunidade de acompanhar o dia a dia das mulheres que constituem a base do $\mathrm{MMC} / \mathrm{SC}$ e de suas famílias, nesses meses pude conhecer outros movimentos próximos dele (o Movimento dos Trabalhadores Rurais Sem Terra, o Movimento da Mulher Trabalhadora Rural do Nordeste, o Movimento dos Pequenos Agricultores, o Movimento dos Atingidos por Barragens, as Comunidades Eclesiais de Base) e participar de encontros e eventos organizados, em vários níveis, pelo ou junto ao MMC/SC. Para conduzir minha pesquisa de campo, portanto, construí junto aos sujeitos que nela se envolveram, uma metodologia que pode ser definida de convivência itinerante e que descreverei mais adiante.

\section{Implicação e eixos de diferenciação}

Ao acabar a entrevista narrativa que realizei com todas as mulheres envolvidas na pesquisa, sempre fazia uma pergunta sobre a percepção e o significado da minha presença nas casas delas e no movimento. Muitas entrevistadas me respondiam, contando o debate gerado na coordenação regional na hora de discutir a minha proposta de ser hospedada nas casas delas. Muitas mulheres se referiram a sentimentos de preocupação e de receio, motivados, sobretudo, por algumas precedentes experiências negativas. As perguntas que circularam, foram: será que conseguiremos nos entender? Ela vai comer o que nós comemos? Ela vai lavar a sua roupa? Essas narrações me davam uma clara percepção do fato que o olhar, a observação e a interpretação das mulheres que participaram da pesquisa me tornaram, na presente realidade, objeto de estudo até antes de minha chegada no campo. Em outras palavras, não era eu quem escolhia deliberadamente minha posição no campo, mas, em boa medida, a recebia ou, pelo menos, a negociava com os outros 
sujeitos envolvidos na pesquisa. Fava (2007) esclarece essa dinâmica através do conceito de implicação: isto é, a produção social da pesquisadora por parte de suas interlocutoras e seus interlocutores no interior da pesquisa. Segundo o autor, são os atores sociais que constroem uma posição para e ao redor do pesquisador, tornando possível a relação de pesquisa e a presença recíproca no campo. A implicação depende fundamentalmente da maneira como ele é vista pelos outros sujeitos da pesquisa, é construída já antes que ele chegue no campo e muda, com o tempo, por efeito de negociações e ao se estruturar a relação.

Entre os eixos de diferenciação mais significativos para a construção da minha implicação por parte das mulheres no momento da minha chegada ao campo, considero as diferenças de classe, a minha pertença ao mundo acadêmico e a minha nacionalidade. Por muitos aspectos, a minha nacionalidade tem se revelado um importante elemento de facilitação do acesso ao campo e de aproximação com as famílias que me hospedaram. De fato, todos os municípios onde morei foram fundados, por volta dos anos de 1950, por famílias oriundas do Rio Grande do Sul e descendentes de imigrantes europeus - principalmente italianos, alemães e poloneses - chegados ao Brasil, sobretudo a partir da segunda metade de 1800. Das vinte e duas militantes do MMC que me hospedaram ao longo de toda minha pesquisa de campo (tanto na fase de exploração quanto na fase intensiva), quatro se definem alemãs ou descendentes de alemães, quatro se definem caboclas, uma de origem russo-polonesa, e treze italianas ou descendentes de italianos. Se considerarmos que, como aponta de Oliveira (2010), no Oeste de Santa Catarina, a identidade de "origem" se estruturou a partir da valorização de uma pertença étnica e em contraposição com os brasileiros ou "caboclos", é fácil imaginar que tipo de memórias e sentimentos despertasse a minha presença nas casas onde eu fui hospedada. Como reconheceram em várias ocasiões, poder me acolher representava para muitas delas e para suas famílias a possibilidade de se reconectar com as próprias raízes, com o mundo do qual provinham os seus antepassados, falar uma língua esquecida ou nunca aprendida, mas que percebiam como íntima e familiar, enfim, acolher uma pessoa da "mesma família" ou da "mesma nação".

Apesar disso, a concepção estática da cultura europeia, que os colonos "de origem" mantiveram e, de alguma forma, construíram; uma concepção baseada em memórias legendárias 
e visões televisivas, junto a juízos prévios quanto ao meu status socioeconômico e à minha pertença ao mundo acadêmico contribuíram para me identificar inicialmente como uma jovem universitária europeia e rica. Segundo Jarry e colaboradores (2006), até nas pesquisas caracterizadas pela partilha do compromisso político feminista e onde pesquisadora e sujeitos da pesquisa são mulheres, se o postulado da irmandade ideal entre mulheres permite à pesquisadora entrar nas redes femininas, no campo, a sua identificação por parte das participantes se baseia, sobretudo: na identidade nacional, na classe socioeconômica e na sua pertença a uma elite intelectual. Por mais que essa representação tenha me causado certo embaraço e não poucos conflitos interiores, eu penso que ela não possa ser considerada simplesmente como um obstáculo a remover ou um limite a aceitar, mas que, pelo contrário, ela deva ser valorizada enquanto um elemento de conhecimento da realidade. Fava (2007), de fato, coloca a implicação como uma chave de acesso crucial ao conhecimento da realidade objeto de estudo. De fato, se ela é reconstruída crítica e reflexivamente, permite entender os modelos de sentido, as dinâmicas internas e a lógica das interações no universo social num dado momento; portanto, é a mediação necessária para compreender as situações de pesquisa, em que entrevistas, discursos, observações são produzidas.

Nesse sentido, interpreto esse tipo de implicação como expressão, por um lado, das enormes diferenças socioeconômicas que caracterizam a realidade brasileira, por outro, da tendência dos movimentos sociais de conceber a opressão em termos de oposições binárias fixas entre, por exemplo, Norte-Sul, pobresricos, trabalhadores-capital, etc. Acredito que essa maneira de conceber a opressão, fruto da aquisição pelos movimentos das categorias de análise da própria pedagogia popular, não seja mais adequada para compreender as complexas e ambíguas mudanças que estão atravessando a realidade brasileira. Ela representa também um dos aspectos sobre os quais refletiram algumas feministas, que tentaram criticar e reinventar a abordagem de Paulo Freire. Weiler (1991), por exemplo, mesmo reconhecendo que uma clara distinção entre opressores e oprimidos caracterizasse o contexto a partir do qual a Pedagogia do Oprimido foi pensada, propõe uma complexificação do conceito de opressão, que considere a possibilidade de simultâneas e contraditórias posições de dominação e opressão. Piano (2006), por outro lado, mostra os 
riscos da fixação da consciência, que, depois de ter tomado conta do negativo, fica ligada a ele, vinculando a ele cada representação de si. A autora, seguindo o rumo traçado pelo feminismo da diferença italiano, sugere uma relativização da opressão como princípio único de identificação e como qualidade existencial capaz de homologar sujeitos diferentes.

Em particular, valorizar a interpretação da pesquisadora por parte das interlocutoras da pesquisa como relevante para alcançar o conhecimento da realidade objeto de estudo significa afirmar que elas são não só informadoras, mas também sujeitos que conhecem e interpretam de maneira igualmente relevante. Reconhecer e promover a competência interpretativa dos atores sociais coincide, provavelmente, com o caráter mais propriamente transformador da pesquisa e torna questionável outra clássica dicotomia: aquela entre teoria e prática.

\section{Práticas de descolonização do olhar}

Se é verdade que a pesquisadora no campo é implicada pelas outras participantes da pesquisa, é verdade também que a própria pesquisadora as implica segundo modalidades epistemológica, ética e politicamente relevantes (FAVA, 2007). Cima (2012), nesse sentido, aponta que:

[...] se não fôssemos ao mesmo tempo pesquisadores e pesquisados, a dimensão do conhecimento se tornaria um desejo de possuir olhares ordenadores, ao fim de reorganizar as vidas dos outros [...] muito frequentemente, somos testemunhas das vozes dos outros para assumir involuntariamente a sua marginalização, para estigmatizá-los ainda mais e para inventar novos estereótipos. (CIMA, 2012, p. 110, minha tradução).

Nesse sentido, pesquisar-se para a pesquisadora significa, em primeiro lugar, aprender a observar, pelo menos em parte, as categorias através das quais percebe a outra, como está em presença da outra e o que a outra representa para ela. De fato, a outra não existe nunca sozinha, mas sim no interior de uma interação e de uma interpretação recíproca. Todavia, compreender como se percebe e nomeia a outra não é uma questão apenas pessoal, porque nós somos frutos de uma história que nos transcende, uma história de colonialismo, colonialidade, marginalização de saberes populares, cultura do silêncio, práticas desumanizantes e resistência etc. As 
feministas pós-coloniais contribuíram para mostrar o quanto esses elementos são significativos até no interior de alianças políticas feministas, desmascarando a postura imperialista que se esconde também atrás de uma opção de solidariedade. Segundo Spivak (2010), este é o caso de muitas feministas brancas e ocidentais, que se constituem como sujeitos de conhecimento, de salvação, de ajuda, através de uma representação das outras como irmãs do terceiro mundo em situação de desvantagem, objeto da sua ilimitada compaixão.

É importante considerar também as categorias interpretativas que a academia cria e utiliza para representar o outro: de fato, em boa medida, o conhecimento do outro é mediado pelo que Bourdieu (2003) define como "inconsciente acadêmico", ou seja, o conjunto de estruturas cognitivas, imputáveis à carreira escolar, que são comuns aos produtos de certo sistema universitário nacional ou aos que se ocupam de certa disciplina num certo momento. É o "inconsciente acadêmico" que determina, por exemplo, o que merece atenção e o que não, o que é importante ou o que deve ser discutido e que influencia decisões cruciais como a escolha dos sujeitos, das teorias de referência e do método. Nesse sentido, a “objetivação participante”, proposta pelo autor, implica considerar reflexivamente não só dimensões como o contexto de origem da pesquisadora, as suas adesões sociais e religiosas, a sua idade, o seu sexo, a sua trajetória pessoal, mas, sobretudo, a sua posição no universo acadêmico e no campo da disciplina, com as suas tradições, os particularismos nacionais, as problemáticas obrigatórias, os valores, os rituais, as obrigações quanto à publicação dos resultados, as evidências compartilhadas, as categorias (nacionais) do conhecimento científico etc. Essa forma de objetivação da relação subjetiva ao objeto examina as condições de possibilidade do conhecimento, portanto, se contrapõe a uma visão da reflexividade como retorno intimista na pessoa privada do pesquisador. Reconhecer o peso do "inconsciente acadêmico" e da posição do pesquisador no universo profissional para as escolhas fundamentais da pesquisa e para a construção do seu olhar interpretativo desmascara a suposta neutralidade do conhecimento, critica a representação dos produtores culturais como livres das determinantes sociais e contribui para questionar a separação entre academia e realidade social, ao colocar a realidade acadêmica como um dos campos de investigação fundamentais no processo da pesquisa.

REVISTA GRIFOS - N. 34/34 - 2013 
De alguma forma, a minha posição me dispõe a uma maior lucidez a respeito do "inconsciente acadêmico",já que eu me coloco no cruzamento de diferentes universos acadêmicos e nacionais. Decidir estudar um movimento social feminista e camponês a partir de uma posição entre fronteiras (não só geográficas, mas também de outra natureza: a fronteira entre teoria e prática ou entre academia e movimentos sociais) implica ter sempre em consideração para quem se fala ou se escreve, explicitar a partir de quais relações, quais contextos e quais realidades se escreve ou se fala, se deparar constantemente com a questão da tradução, entendida como processo complexo, não somente linguístico, mas também político e cultural. Traduzir muitas vezes significa experimentar a distância entre o que se deseja dizer e o que se pode dizer, a insuficiência das palavras, o silêncio, ao mesmo tempo, é política e teoricamente indispensável para criar alianças políticas e epistemológicas (COSTA; ALVAREZ, 2009). Estar na fronteira pode dar a sensação desagradável de não se sentir nunca em casa e de não ter pontos de referência estáveis, mas a fronteira é também um lugar de lucidez, criticidade e criatividade de pensamento, um lugar que autoriza corajosos gestos de ruptura e leituras inéditas iluminadas por outros olhares.

\section{Metodologia de convivência itinerante e práticas de superação das distâncias}

A posição que os sujeitos da pesquisa constroem para tornar possível a presença da pesquisadora no campo não é fixa, pode ser negociada e muda com a transformação da relação. Nesse sentido, é importante para a pesquisadora ser consciente das modalidades como ela mesma implica suas interlocutoras, e realizar umas práticas que permitam reduzir as assimetrias de poder e as distâncias. Para mim, se revelou muito importante participar das atividades que caracterizam a vida cotidiana das agricultoras, como: tirar leite, trabalhar na lavoura e na horta, cozinhar, limpar a casa, lavar a roupa, cuidar das crianças. Isso, se por um lado, implicou que eu aderisse e, em alguma medida reforçasse, as normas de gênero que vigoram no contexto no qual realizei a minha pesquisa de campo, gerando em mim não poucos conflitos; por outro lado, permitiu que eu fosse aceita, reformulou as representações através das quais eu era identificada e tornou possível a construção de uma relação mais próxima e mais verdadeira com as mulheres envolvidas na 
pesquisa. De fato, ao longo da minha permanência, eu recebi muitos feedbacks positivos a respeito disso. Em seguida, transcrevo um episódio que anotei em meu diário de campo.

De repente Lenir, que logo antes tinha me perguntado se eu era de família rica, contou para Luciane que eu tinha cozinhado bolinhos de abóbora, se referindo a mim como "essa bicha". Luciane a olhou, maravilhada que ela usasse essa expressão para mim e então Lenir continuou "bicha querida" e me deu um beijo. De noite, quando todas as mulheres foram embora e ficamos só eu, Salete e ela, Lenir, me abraçando e me olhando nos olhos, me disse: "vai ficar na história que hoje eu te tive comigo, você me pareceu que nem nós: uma camponesa, muito simples, muito dada!" (NOTAS DE DIÁRIO DE CAMPO, 10 de setembro de 2012).

Apesar das categorias sociais e culturais ativas na identificação e representação recíproca e dos outros elementos problemáticos que descrevi antes, a construção de uma relação de proximidade representa um pressuposto fundamental para alcançar o conhecimento da realidade social a partir do ponto de vista dos sujeitos da pesquisa, objetivo de uma investigação baseada na abordagem etnográfica, ainda mais quando se quer ser fiel a uma perspectiva de educação popular. Desse ponto de vista, a metodologia da convivência itinerante que eu construí junto aos atores sociais envolvidos na pesquisa, adquiriu múltiplos significados, permitindo-me questionar a contradição entre pesquisadora e sujeitos da pesquisa, opção científica e opção política, afetividade e pesquisa, ação e reflexão. Entre outras coisas, ela tornou possível que eu me deixasse conscientizar pelas mulheres que me hospedaram segundo uma intuição fundamental de Paulo Freire.

Oliveira (2009) sublinha o significado da convivência metodológica para a educação popular:

[...] compreender e dialogar exige mais do que uma visita; significa uma vivência próxima, afetiva e comprometida. Muitos aspectos das relações sociais nessas comunidades, suas histórias, desafios e saberes só são percebidos desta forma [...] Conviver é mais do que visitar e, não sendo algo que possa ser delegado, requer um envolvimento pessoal de observação, questionamento e diálogo. Somente olho no olho com o outro e, com ele convivendo, é que se pode detectar e compreender posições políticas e informações que nos são fornecidas sobre dada realidade. (OLIVEIRA, 2009, p. 314-315) 
A itinerância, por outro lado, me permitiu experimentar concretamente uma dimensão fundamental defendida pelo mesmo Movimento das Mulheres Camponesas: a interdependência. Deslocar-me, de semana em semana, de uma casa para outra exigiu de mim uma grande disponibilidade de adaptação aos ritmos, aos costumes, às condições, às propostas das famílias que visitei; ao mesmo tempo que me colocou numa condição de profunda vulnerabilidade, em que eu dependia das mulheres que me acolheram para toda necessidade básica: comer, dormir, me deslocar, me cuidar, receber atenção e carinho, me sentir segura etc. $\mathrm{O}$ que eu vivi no meu próprio corpo me conduziu a rejeitar uma suposição que se afirmou especialmente a partir da modernidade, isto é, o ideal da autossuficiência, e me deu clareza das múltiplas dependências que me ligam ao mundo. $\mathrm{O}$ feminismo italiano da diferença tem trabalhado muito sobre a necessidade de recuperar um sentido positivo da dependência. Segundo Tommasi (apud DIOTIMA, 1995), toda filosofia contemporânea criticou a visão de subjetividade baseada no ideal da autossuficiência, da independência do corpo e do isolamento dos outros, que se afirmou a partir de Descartes. Mas, se a filosofia masculina contemporânea questionou esse ideal através de uma crítica interna daquele "eu" que, já volitivo e racional, se descobriu residual e débil, a desmistificação feminista tem origem nas relações e no reconhecimento dos laços de dependência que nos conectam ao mundo. Praetorius (2011) mostra como a ideia ocidental de liberdade nasceu numa sociedade que não reconhecia a pertença de muitas categorias de pessoas à humanidade. Os pensadores da antiga Grécia dividiram o mundo em duas esferas: uma superior, simbolicamente masculina, livre e preocupada com o espírito; e a outra inferior, simbolicamente feminina, dependente e preocupada com o serviço. A ideia de liberdade que desde então se afirmou coincide com a não dependência, mas a independência de algumas categorias era e continua sendo possível só graças ao trabalho não reconhecido de outros, sobretudo das mulheres. A autora, portanto, propõe uma concepção não dualista da liberdade a partir da consideração de que todos nós somos paridos, que todos nós viemos ao mundo na forma de uma relação e que, desde o começo, somos parte de uma rede de relações geracionais. $\mathrm{O}$ fato de termos sido paridos nos marca por toda a vida: somos seres vulneráveis e dependentes, precisamos do outro e da outra, 
a nossa liberdade é relacional. Essa visão torna possível conciliar a liberdade com o reconhecimento das múltiplas relações em que mergulhamos e nos permite entender a autonomia não em termos de independência, mas em termos de redução das dependências (ibidem).

\section{Considerações finais: o reconhecimento de autoridade como opção popular e feminista}

Assim, se, por um lado, a minha chegada numa nova casa exigia sempre certo desempenho para negociar a gestão do tempo e do espaço, como também a minha acolhida no contexto familiar e as atividades da minha pesquisa, por outro lado eu tive sempre clareza que eu me movia porque uma mulher me entregava à outra, porque alguém era disponível a me enviar e alguém era disponível a me receber. Os meus deslocamentos eram possíveis em virtude da mediação de outras mulheres: as que me tinham hospedado precedentemente ou a coordenadora responsável pela minha permanência no município. Trata-se de uma mediação, que nem sempre se realizava na minha presença, mas que tinha o efeito de facilitar os meus movimentos no campo. Percebi sempre com muita clareza o quanto as mulheres envolvidas na minha pesquisa se sentiam responsáveis por mim, tanto é que muitas vezes elas usavam a categoria de "mãe" para se definirem e se posicionarem a meu respeito, seja falando comigo, seja falando com outras pessoas sobre mim.

O uso dessa categoria por parte das informantes era motivado não só pela diferença de idade que me aproxima às suas filhas e filhos - de quem eu tomei simbolicamente o lugar, ocupando fisicamente o espaço que eles deixaram para ir à cidade em procura de trabalho ou estudo; mas também por causa do posicionamento que eu assumi em razão de uma prática política popular e feminista, que eu defino, usando a expressão proposta pelo feminismo italiano da diferença, "reconhecimento de autoridade" (DIOTIMA, 1995). De fato, toda minha pesquisa nasce da vontade de me inserir num "discipulado" de práticas políticopedagógicas que considero relevantes não somente a respeito da realidade na qual se inserem, mas também numa dimensão mais global; de me dispor, antes de tudo, a apreender e a me deixar conscientizar pelas mulheres protagonistas da minha pesquisa; de experimentar uma intuição fundamental da educação popular:

REVISTA GRIFOS - N. 34/34 - 2013 
a confiança intelectual e moral nos oprimidos e nas oprimidas, em razão da sua maior lucidez na análise do sistema opressivo e da sua sensibilidade solidária em denunciar seu caráter injusto (GIRARDI, 2013); enfim, de reconhecer autoridade a práticas político-pedagógicas muitas vezes ignoradas, não valoradas e consideradas "miudezas"2 não só pela sociedade e pelas mídias, mas também por movimentos sociais, comprometidos na mesma luta, mas caraterizados por uma lógica masculina e machista, e, às vezes, pelas próprias mulheres.

Fundar a minha investigação a partir do reconhecimento de autoridade teve algumas importantes consequências. Em primeiro lugar, permitiu-me ler as histórias dessas "mães" não só em termos de opressão, subalternidade, violência, descriminação, mas também considerando a sua grande contribuição políticopedagógica (TOMMASI apud DIOTIMA, 1995). Por outro lado, isso determinou algumas consequências políticas significativas para o contexto da minha pesquisa e talvez seja esse um dos elementos como se expressou a relevância social do processo de investigação. De fato, o meu reconhecimento público de autoridade para o MMC e especialmente para as mulheres concretamente envolvidas na minha pesquisa - reconhecimento que se deu não só através da escritura da minha tese, mas também em todas as ocasiões em que eu pude falar nos jornais, nas rádios, nos debates públicos, nos eventos acadêmicos etc., enquanto universitária interessada no MMC - contribuiu para que as riquezas produzidas pelo $\mathrm{MMC}$ adquirissem visibilidade e, sobretudo, a marca da parcialidade feminina, contrastando assim com um problema muitas vezes identificado pelas mulheres: a apropriação das suas práticas e conquistas por parte de sujeitos supostamente neutros, que acabam apagando a contribuição das mulheres. Enfim, considerando que se reconhece autoridade a quem oferece mediações capazes de canalizar os próprios desejos, fundar a minha pesquisa sobre um reconhecimento de autoridade junto à mediação das mulheres me permitiu realmente «ser» na pesquisa e tornou possíveis deslocamentos no campo e cruzamentos de fronteiras.

Uma última consideração é relativa à questão da devolução dos dados. Considero fundamental a fase de retorno final dos resultados, sobre o que Oliveira (2009) foca a atenção, explicitando que ela deve se dar tanto através da comunicação das informações quanto da efetiva contribuição social. Nesse
2 Com essa palavra se indicam alimentos como as hortaliças e as verduras, geralmente cultivados pelas mulheres, que não geram lucro, mas que são fundamentais para o sustento da família. 
sentido, em conformidade com a opção de compartilhar com sujeitos, grupos e comunidades envolvidos na pesquisa o material científico produzido, projetei, junto à coordenação do $\mathrm{MMC} /$ $\mathrm{SC}$, alguns encontros de discussão comum dos resultados a serem realizados junto às mulheres que me hospedaram em suas casas e outras militantes eventualmente interessadas e que sirvam também como momentos de formação. Todavia, numa ótica de superação da contradição entre pesquisadora e interlocutoras da pesquisa, é necessário complexificar o conceito de devolução: de fato, se os sujeitos da pesquisa estão envolvidos numa relação de troca constante, a devolução se dá segundo várias modalidades e em várias etapas do processo da investigação. Nesse sentido, eu considerei oportunidades de devolução importantes todas as ocasiões em que me propus a dialogar com as mulheres do MMC sobre as minhas interpretações dos fatos sociais e em que escutei a opinião delas; ou quando, depois de tê-las transcrito, devolvi as entrevistas coletadas para que as participantes da pesquisa pudessem introduzir eventuais modificações, que as ajudassem a se expressar de uma forma mais próxima à sua intenção; enfim, todas as vezes que eu voltei para visitar as mulheres que me hospedaram ou simplesmente escrevi para elas referindo os avanços e as dificuldades do meu trabalho de escrita.

\section{Referências}

BOURDIEU, Pierre. Lobjectivation participante. Actes de larecherche em sciencessociales. Vol. 150, decembro 2003, p.43-58.

CIMA, Rosanna.Pratiche narrative perunapedagogiadell'invecchiare. Milano: FrancoAngeli, 2012.

CLIFFORD, James. Sobre a autoridade etnográfica. Antropologia e literatura no século XX. Rio de Janeiro: UFRJ, 2008.

COSTA, Claudia de Lima; ALVAREZ, Sonia E. Translocalidades: por uma política feminista da tradução. Revista de Estudos Feministas. Sept./Dec. 2009, pp. 739-742.

SANTOS, Boaventura de Souza. Um discurso sobre as ciências. Porto: Afrontamento, 1987.

DIOTIMA. Oltre l'uguaglianza. Le radici femminili dell'autorità. Napoli: Liguori, 1995. 
TOMMASI, Wanda. Il lavoro del servo. In: DIOTIMA. Oltre

l'uguaglianza. Le radici femminili dell'autorità. Napoli: Liguori, 1995.

FAVA, Ferdinando. Lo Zen di Palermo. Antropologia dell'esclusione.

Milano: FrancoAngeli, 2007.

GIRARDI, Giulio. Educazione dalla dipendenza ala pratica dela libertà. Disponível em: <www.amistrada.net>. Acesso em: 12 abr. 2013.

GROSSI, Miriam (org). Trabalho de campo e subjetividade. Florianópolis: UFSC, 1992.

JARRY et al. Quelques réflexions sur le rapport de jeunes chercheuses féministes à leur terrain. Terrains \& travaux. N.10, Janeiro 2006, pp.177-193.

MAYO, Peter. Gramsci, Freire e l'educazione degli adulti. Possibilità di un'azione trasformativa.Sassari: Carlo Delfino editore, 2007.

MORIN, Edgar; CIURANA Émilio R.; MOTTA, Domingo R. Educare per l'era planetaria. Roma: Armando editore, 2004.

OLIVEIRA, Maria de. Pesquisa e trabalho profissional como espaços e processos de humanização e de comunhão criadora. Cadernos Cedes. Campinas, vol.29, n.79, sept-dec, 2009, pp.309-321.

OLIVEIRA, Ancelmo P. de. "Brasileiros" e "de origem" na oralidade cotidiana escolar: emblemas de uma tensão interétnica. Dissertação (Doutorado em Educação) - Programa de Pós-Graduação em Educação. Florianópolis: Universidade Federal de Santa Catarina, 2010.

PIANO, Maria G. La pedagogía del oprimido. In: MONFERRER, Dolors; GUADAS, Isabel, A.; ORTIZ, Pascual, M.; GUADAS, Pep A. (orgs). Fórum Paulo Freire V encuentro internacional. Sendas de Freire, opresiones, resistencias y emancipaciones em unnuevo paradigma de vida. Xàtiva: Institut Paulo Freire de España y Crec, 2006.

PRAETORIUS, Ina. Penelope a Davos. Idee femministe per un'economia globale.I quaderni di via dogana. Milano, 2011.

SPIVAK, Gayatri, C. Pode o subalterno falar? Belo Horizonte: Editora UFMG, 2010.

WEILER, Kathleen. Freire and a Feminist Pedagogy of Difference. Harward Educational Review.Vol.61, n.4, Winter 1991, pp.449-475. 


\title{
CREATING A POPULAR AND FEMINIST METHODOLOGY OF RESEARCH WITH THE PEASANT WOMEN MOVEMENT IN SANTA CATARINA
}

\begin{abstract}
Through the analysis of some dimensions of the research that I am carrying out since 2012 with the Peasant Women Movement in Santa Catarina, I intend to dialogue with the international debate about the crisis of the modern conception of scientific method and the search for methodological practices that enable the overcome of its mortifying dualistic view. In particular, I'll examine the implications of the popular pedagogy and feminism as theoretical, political and existential options for methodological choices. In this sense, through an auto-ethnographic report about the methodology of "itinerant coexistence" adopted in my research, I'll propose the investigation as a dialogic and intersubjective construction, in which the researcher, when inquiring, investigates herself and, on the other hand, is investigated; as the participants, when inquired, are able to carry out the research and research themselves.
\end{abstract}

Keywords: Field research. Itinerant coexistence. Dialogicity. 